\title{
A Survey on Use of Colour Pens in Examinations Among the Dental Students
}

\author{
S. Balamithra ${ }^{1}$ and M.P. Brundha ${ }^{1 *}$ \\ ${ }^{1}$ Department of Pathology, Saveetha Dental College, Saveetha Institute of \\ Medical and Technical Sciences, Saveetha University, Chennai, India \\ ${ }^{1 *}$ Associate professor, Department of Pathology, Saveetha Dental College and Hospitals Saveetha \\ Institute of Medical and Technical Sciences Saveetha University, Chennai, India
}

\begin{abstract}
The aim of the study is to find the effectiveness of use of colour pens among the students. Colour pens used in examinations make it easier for the students and teachers to do their task. .Highlighting the important points makes the students to study and score marks easily as from a teacher's point of view it makes paper corrections easier. The use of colour pens in exams has been found to be excellent which makes the exam paper colourful and the exam paper looks neat. There are several methods in using colours in exams either for underlining or for writing the important points with colour pens. A survey is conducted among 100 students with 15 questions in google forms. The students attending the survey are from Saveetha Institutes of medicine and technical Sciences.results were entered in the excel sheet and analysed through SPSS statistical platform. From the results of our study, we conclude that the use of colour pens during an exam increases the grade of the student's performance. Eventhough is not statistically significant, in our study we found the females use colour pens in exams more efficiently than males. Also, the study proved that instead the use of colour pens consumed more time than usual, by practice the time can be adjusted sufficiently along with the colour pen use will increase the performance level in their exams.
\end{abstract}

KEY WORDS: STUDENT,COLOUR PENS, EXAM, TIME, GRADES.

\section{INTRODUCTION}

Blooms taxonomy is a set of three hierarchical models used to classify educational learning objectives into levels of complexity and specificity. The three list covers the learning objectives in cognitive, affective and sensory domains. The cognitive domain list has been the primary focus of the most traditional education and is frequently used to structure curriculum learning objectives,

\section{ARTICLE INFORMATION}

${ }^{*}$ Corresponding Author: brundha.sdc@saveetha.com Received 6th June 2020 Accepted after revision 4th August 2020 Print ISSN: 0974-6455 Online ISSN: 2321-4007 CODEN: BBRCBA

Thomson Reuters ISI Web of Science Clarivate Analytics USA and Crossref Indexed Journal

\section{Clarivate}

NAAS Journal Score 2020 (4.31) SJIF: 2020 (7.728)

A Society of Science and Nature Publication,

Bhopal India 2020. All rights reserved.

Online Contents Available at: http//www.bbrc.in/

Doi: http://dx.doi.org/10.21786/bbrc/13.7/53 assessments and activities. It is used in problem solving situations by applying the acquired knowledge, facts, techniques and rules. Learners should be able to use prior knowledge to solve problems, identify connections and relationships and how they apply in new situations. Knowledge is the foundational cognitive skills and refers to the retention of specific, discrete pieces of information like facts and definitions. Assessment is an essential element to any educational process(Adams, 2015). Summative assessment is used to measure what students have learnt at the end of a course and moves to higher levels (Umar and Majeed, 2018).

The Neuro-linguistic programming underlying principles have been applied in various performance related and learning contexts. It was introduced by Richard Bandler and James Grinder. Key concepts in Neuro-linguistic

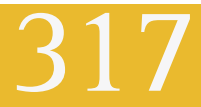


programming is appreciation and understanding individuals to use a representational system based upon each of the sense modalities to understand and interpret the world. These systems are visual, auditory, kinaesthetic, olfactory and gustatory Learning is the dynamic process by which the meaning is created by reciprocal feedback and not simply the transmission of information from one individual to another individual. As Neuro-linguistic programming consists of a wide range of techniques that are held to be effective or useful, rather than coherent theory, it is perfectly acceptable to apply a selected number of these techniques in any particular situation. The strength and weakness of Neuro linguistic programming are described with and recognise the reference to its origin, previous research and comments from critics and supporters (Kudliskis and Burden, 2009).

Mechanical learning has been widely used in image analysis and processing for the purpose of letting the computer recognise specific aspects like colour, shape, texture, size and position. Colour is one of the most important aspects in vision, since it is used generally to discriminate and recognise information. The colour is chosen due to the importance given by humans to this attribute. Also, colour is used in main filter criteria in object recognition and tracking. The effect of the colour is studied from the point of view of the most popular colour spaces available in imaging. The colour is used as a specific wave frequency with a certain amplitude and longitude is not trivial or natural to human beings, it created a system that helps to describe the colour in a more natural and ordered way (Chavolla et al., 2018). Effective assessment is one of the most challenging aspects of teaching. The testing effect is the well demonstrated idea that recalling information in a testing situation is more beneficial than re-reading or re-studying the information(Jensen, Berry and Kummer, 2013).

Examination is an assessment intended to measure a test taker's knowledge, skill, aptitude, physical fitness, or classification in many other topics. A test may be administered verbally, on paper, on a computer, or in a predetermined area that requires a test taker to demonstrate or perform a set of skills. However, each colour represents each meaning here we see some of the colours meaning. Green colour is usually for concentration which improves focus on studies, orange colour is for welcoming and mood lifting colour for learner, which in turn promotes comfort and improves neural functioning, blue is the best for learning situations which are challenging and blue ink, blue paper or blue highlighting can be used to help reader to improves reading comprehension too. (Florea and Radu, 2007). Each colour has a different type of wavelength for example red has more than blue. That is why it is used in traffic signals to stop the vehicles and in correction of paper red ink is more highlighting one for the students to correct their mistakes very easily so that next they won't repeat the same mistakes in their next exams or test. Colour is the most beautiful creature of the world, without the colors the world would be in black and white which is very awful.(Umar and Majeed, 2018)

The main advantages of using colour in exams is to highlight the important points in paper so that evaluators may easily correct the papers. The most disadvantage is that time management in exams is the most and foremost point in the exam . Some may have time in writing in colour pen use in exams and some may not. Students' performance in exams is one of the primary ways. It impacts on students to pass exams (Devine, 2014). Range of student performance based on academic ability, systemic differences in how different populations of students perform on exams potentially contribute to unequal retention of demographic groups.

Students tend to approach learning superficially when they expect tests to have restricted response questions (e.g. questions from which a student chose from a set of answers like multiple choice questions) (Wright, Eddy and Wenderoth, 2016). The format of the exam also influences how students engage with course material. When students expect a test containing constructed response questions (e.g., questions for which students must generate the response: short answers, essay, graphing/drawing) they tend to take a deeper approach to learning and taking notes that concentrate more on main ideas and core concepts ((Mascolo, Alfonso and Flanagan, 2014).

Exam format can also have a differential impact on students as many studies have demonstrated that males tend to perform better on restricted response questions and women tend to perform better on constructed response questions (Mazzeo, Schmitt and Bleistein, 1993). One way of evaluating the cognitive level of exams and their question is to categorise each question according to bloom's taxonomy of cognitive domains(Adesoji, 2018). Learning taxonomies or classification are commonly used as a way of describing different kinds of learning behaviour and characteristics. The original taxonomy of three parts or domain and these are the cognitive, the affective and the psychomotor. The key categories of psychomotor competence capture the development in learning from initial exposure to final exposure, an unconscious master (Bolloten, 2012). The cognitive domains involve the development of mental skills.

\section{MATERIAL AND METHODS}

Sample collection: A survey was conducted among 100 students of Saveetha Dental College and Hospital in the month of November 2019. Nearly 12 valid questions had been prepared and circulated among the students and answers were recorded.

Inclusion Criteria: Selection criteria include all the students of Saveetha dental college who are willing to participate in the study. First, second, third and final

year Undergraduate dental students Exclusion Criteria: Students who were not willing to participate were 
excluded from this study. postgraduate students and interns were excluded.

Sampling method: In the present study,the sampling method used is the Random sampling method.

Data Collection and Tabulation: The responses were entered into the excel sheets and then tabulation of the data finally and the question comparison was done. The representation of the data is through the bar graph.

Statistical Analysis: The statistical software used IBM SPSS V22.The statistical tests used were descriptive analysis and Chi Square analysis. Significant $p$ value was set at $<0.05$.

\section{RESULTS AND DISCUSSION}

In the present study, the study population responded were $34 \%$ of the first year students, $49 \%$ of the second year students, $12 \%$ of the third year students, $4 \%$ of the fourth year students and $1 \%$ were postgraduate students (Figure 1). according to gender distribution, we had studied $72 \%$ of the females and 28\% of males (Figure 2). Figure 3 shows 92\% that the majority of the students use colour pens in exams while $8 \%$ of them do not use colour pens. Nowadays students use colour in the examination. Certain colours produce the certain wavelength in the way to give meanings.For Red colour has the high colour wavelength so that for correction of papers red ink pen is used, so it becomes easy for the students to rectify the mistakes(Reed et al., 2014) Figure 4 shows frequency of colour usage are 44\% are occasional users, $40 \%$ are frequent users and 16\% always use colour pens in exams. Figure 5 shows the way of usage includes either by underlining or writing in colour pens itself both of the way of use.63\% use for both underlining and writing in colour pens, 20\% for underlining and 17\% for writing in colour pens.

Figure 1 In this Pie Chart Blue colour represents the first year students which is $34 \%$, Green colour represents second year students which is $49 \%$, sandal colour represents the third year students which is $12 \%$, Purple colour represents the fourth year students which is $4 \%$ and yellow colour represents post graduate which is $1 \%$.

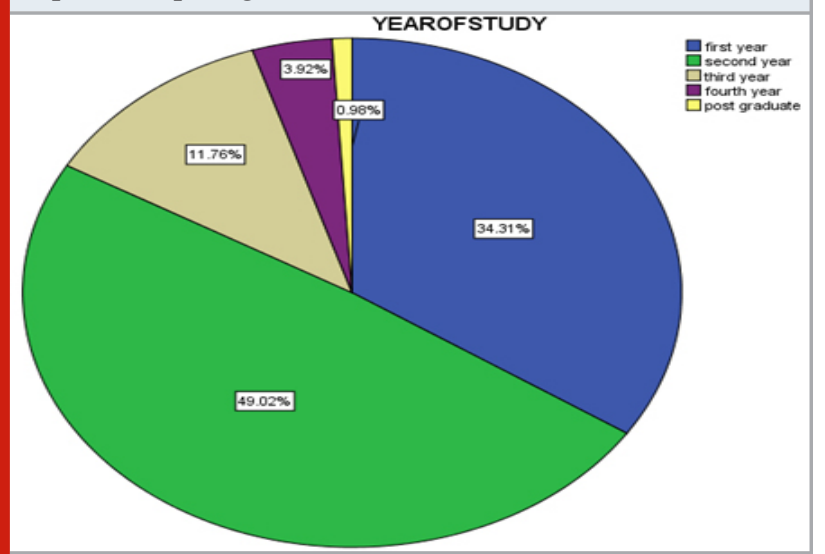

Figure 2: Pie Chart represents the gender. Blue colour represents the female which is $72 \%$ and green colour represents the male which is $28 \%$

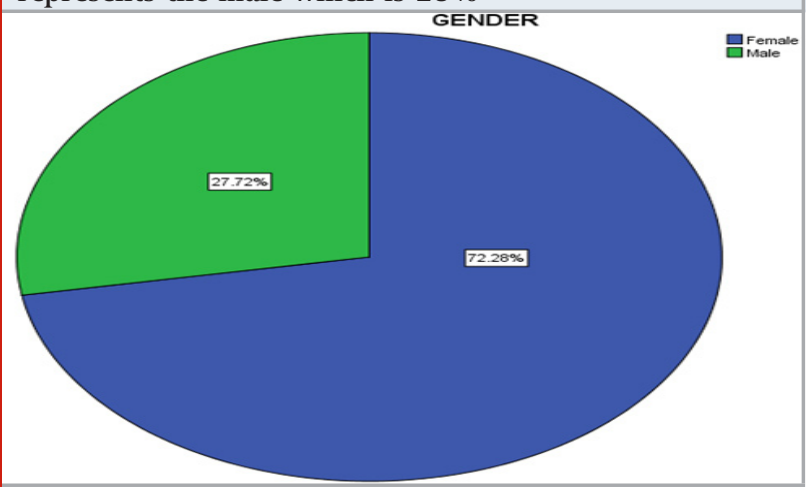

Figure 3: In this Pie Chart blue colour represents the colour pens used in exams which is $92 \%$ while green colour represents the colour pens are not used in exam which is $8 \%$

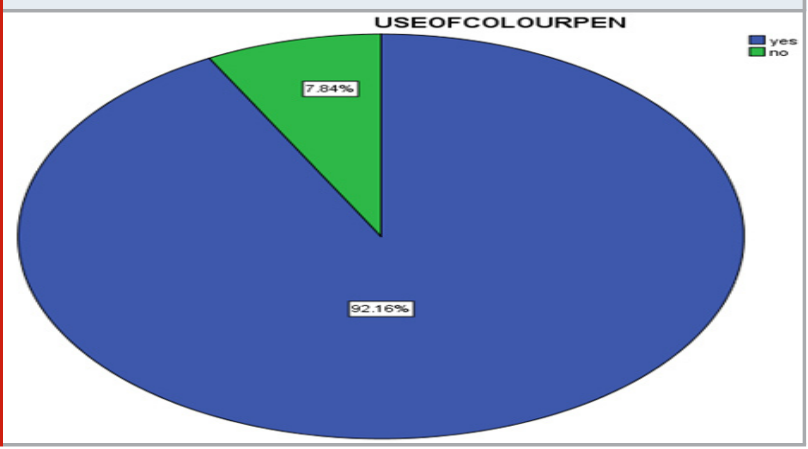

Figure 4: Shows that the majority (43.14\%) of the study population, occasionally use colour pens in exam (green), followed by $29.41 \%(\mathrm{khaki})$ use the colour pens frequently in exams and $27.45 \%$ (blue) always use colour pens in exams.

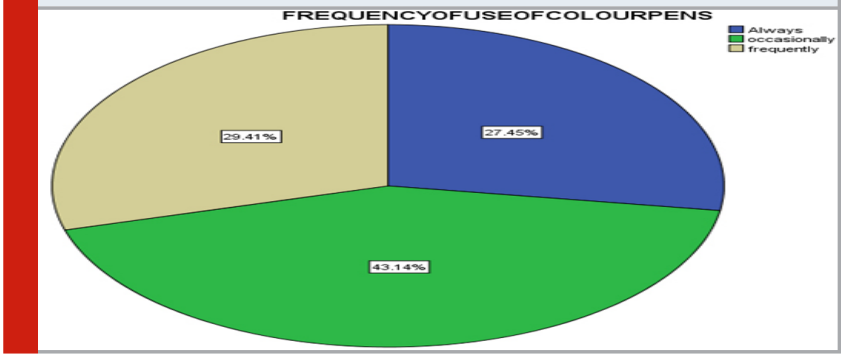

The students nowadays use colour pens for both underlining and writing in colour pen itself. But in a separate point of view that is underlining and highlighting the point separately most of them i.e20\% uses underlining and 17\% least one uses writing in colour pens.Figure 6 shows the method of colour use is a very crucial thing in exam point of view. Most of the students in this generation uses pen in highlighting the points that is $63 \%$ of students, least commonly that is $21 \%$ of them uses for heading, and $16 \%$ of them uses for decoration and no one uses colour pen for the 
diagrammatic purpose .Colour shades may be contrast and same colour. Figure 7 shows $84 \%$ uses contrast colour while $16 \%$ use the same colour. Here the contrast colour means different colours.

Figure 5 Blue colour shows the colour pen used for underlining which is $19 \%$, Green colour shows colour pens used for writing itself which is $17 \%$ and khaki colour indicates the colour pen is used for both underlining and writing in colour pen itself which is $64 \%$

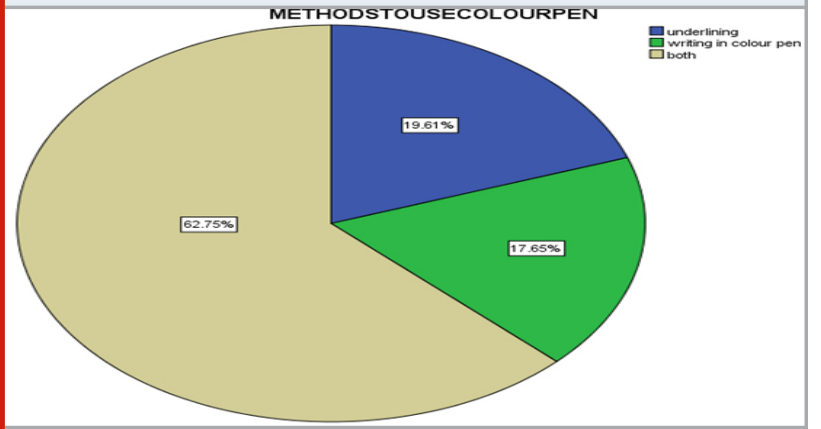

Figure 6 shows the response to the conditions where the colour pens used. Blue colour represents the colour pens used for headings which is $21 \%$, Green colour represents the colour pen used for decoration which is $16 \%$ and sandal colour represents colour pens used for highlighting the important points which is $63 \%$.

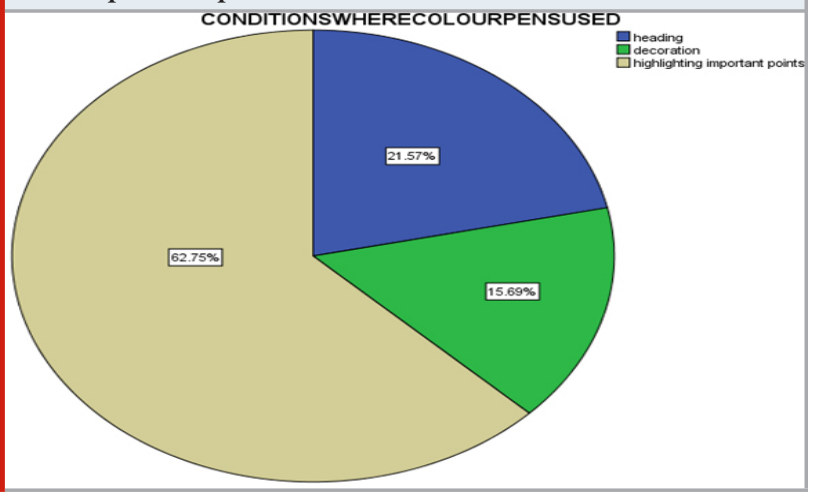

Figure 7: Represents the types of colour shades used. Blue colour represents the percentage of students use contrast colour which is $84 \%$ and green colour represents the same colour which is $16 \%$

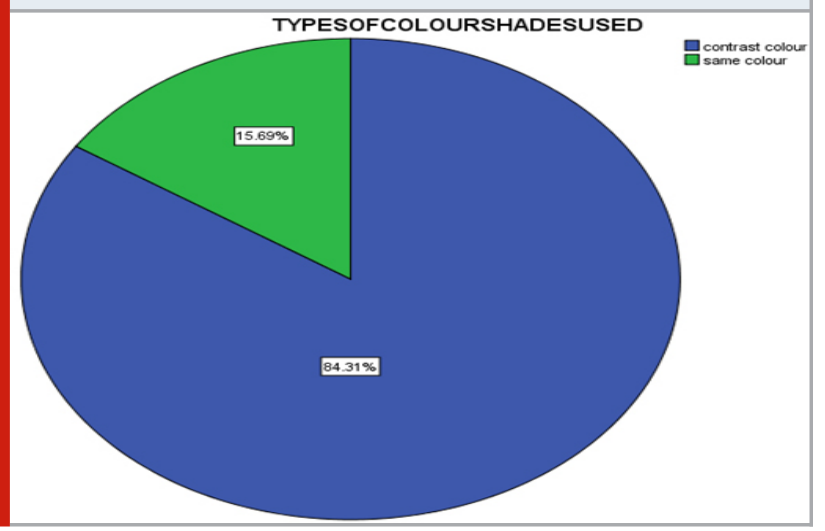

The same colour seems to be monotonous for teachers for corrections while different colours seem to be presenting in good manners. The way of use of colours through colour pens is 68\%, 25\% uses colour pencils, 5\% uses sketches in exams. Colour pens are used by most of the students so it is easy for students in highlighting the points and the least one is sketch pen use which is difficult in use of colour in exams due to its thickness. (Kim et al., 2011)

Figure 8 shows that 76\% have sufficient time to use colour pens in exam and 23\% do not have time to use colour pens. Time is the most important factor in exams. There should be proper time management in exams. Most of the students nowadays use time efficiently in exams. A study has shown that time management has a relation between the character development and academic performance of students (Misra and Castillo, 2004).

Figure 8 represents the time management in use of colour in exams. $76 \%$ of the students opt that they manage time with use of colour pens in exams(blue) and 23.53\% of the students opt that they cannot manage time with use of colour pens in exams(green).

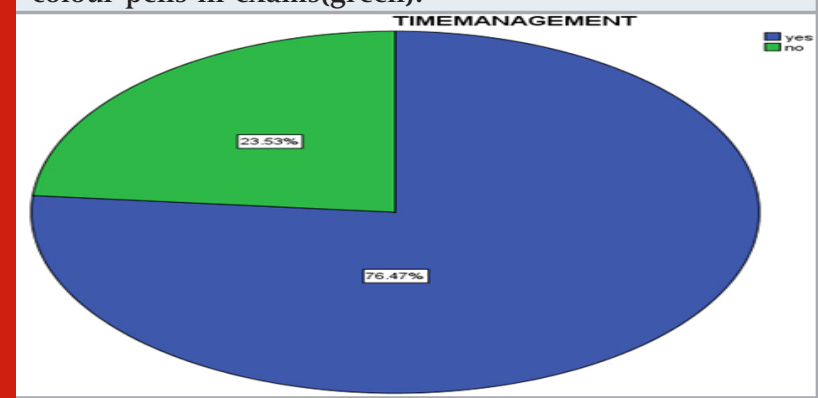

Figure 9: Represents that $86.27 \%$ of the students agreed that there is a definite increase in the grades if they use colour pens in exams. The remaining $13.73 \%$ of students did not agreed it.

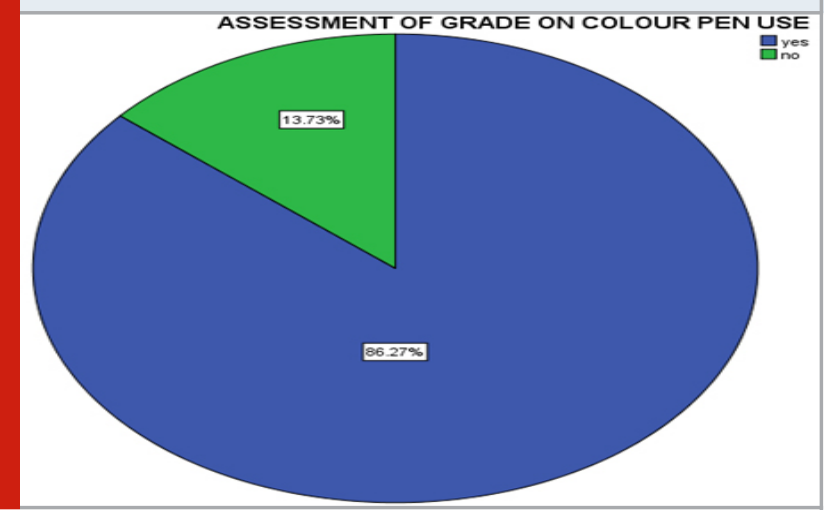

Figure 9 shows 86\% shows increase in grades while in $14 \%$ of them there is no increase in grades. The most important aim of the exam is to get more marks in the exam. Comparison of grade and time management, it shows that most of the students use colour pen in exam wisely and getting grades more.Figure 10 shows Colour preferences which differs from person to person. Pink, 
green and purple colour is preferred by 20\%, Orange colour preferred by $18 \%$, Black is preferred by $21 \%$ and brown is preferred by $2 \%$. Nowadays, the students in exam use five times in exam which is the least number of times in use, but the maximum number of uses of colour pen is twenty times which is used by least populations (He et al., 2016).

Figure 10: Represents the preference of colour by the students. Pink, green and purple colour is preferred by $20 \%$ of the students, Orange colour preferred by $18 \%$ of them, Black is preferred by $21 \%$ and brown is preferred by $2 \%$ of the study population.

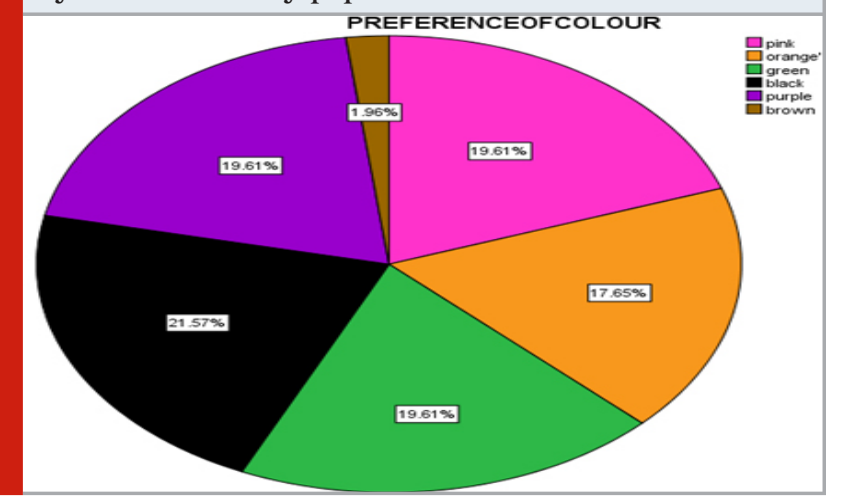

when we compared the gender association with colour pen usage(figure 11-14) we found that the majority of females use the colour pens more in exams than males. However, in the Chi square analysis, it was found that the $\mathrm{P}$ value is $0.421(>0.05)$ which is not significant, also we obtained that the majority of the females agreed that their grades will increase with the use of colour pens in exams than the males. However the difference is not significant statistically( $P$ value is 0.226$)$. Majority of females use colour pens for both underlining and writing the important points in the exams than the males. However the difference is not significant statistically. The $\mathrm{P}$ value is 0.506 ( $>0.05)$. Finally, we found that a majority of females manage the time of examination very

Figure 11: Shows the association between the gender and Frequency of use of colour pen in examination. $\mathrm{X}$ axis represents the Gender and $\mathrm{Y}$ axis represents the frequency of use of colour pens in examination. Majority of females use the colour pens more in exams than males. However, in the Chi square analysis, it was found that the $P$ value is $0.421(>0.05)$ which is statistically not significant.

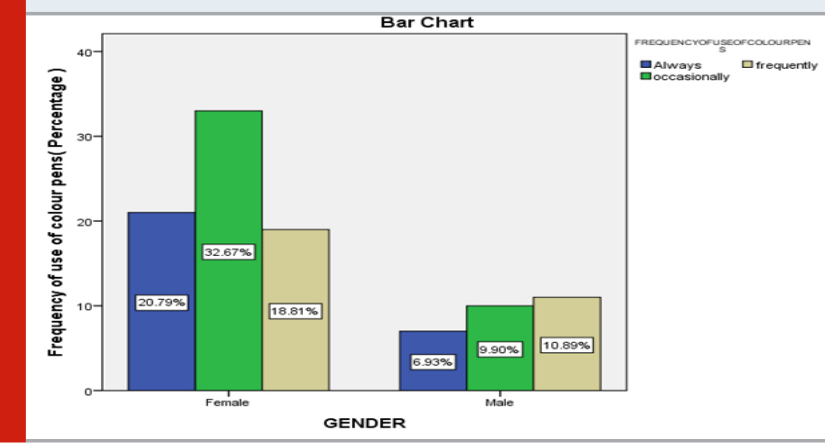

well along with the use of colour pens than the males in our study. However the difference is not significant statistically. The $\mathrm{P}$ value is 0.506 (>0.05).

Figure 12: Represents the association between the gender and percentage responses for increasing grade on colour pen usage. $\mathrm{X}$ axis represents the gender and $\mathrm{Y}$ axis represents the percentage responses for increasing grade on colour pen usage. majority of the females agreed that their grades will increase with the use of colour pens in exams than the males. However the difference is not significant statistically. The $\mathrm{P}$ value is 0.226 which is statistically insignificant.

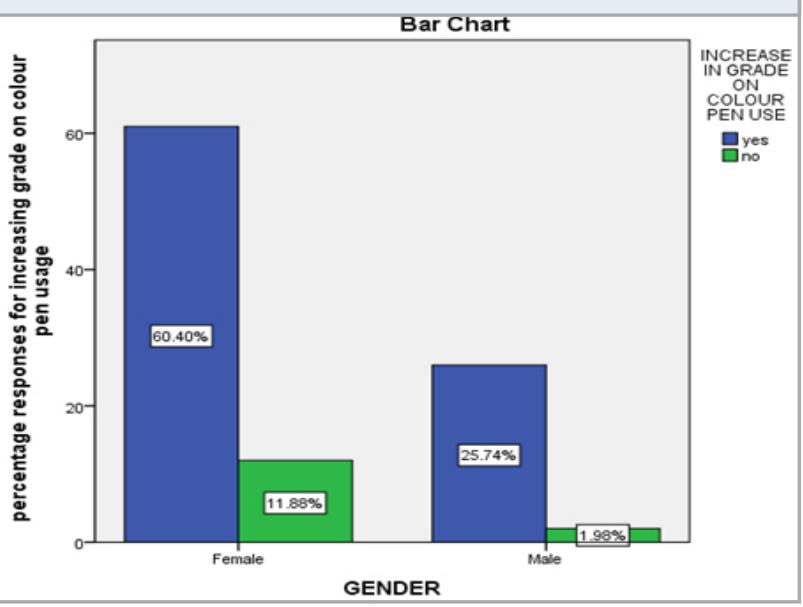

Figure 13: Represents the association between the gender and percentage responses for me on colour pen usage. $\mathrm{X}$ axis represents the gender and $\mathrm{Y}$ axis represents the percentage responses for methods of using colour pens. Majority of females use colour pens for both underlining and writing the important points in the exams than the males. However the difference is not significant statistically. The $\mathrm{P}$ value is 0.506 (>0.05).

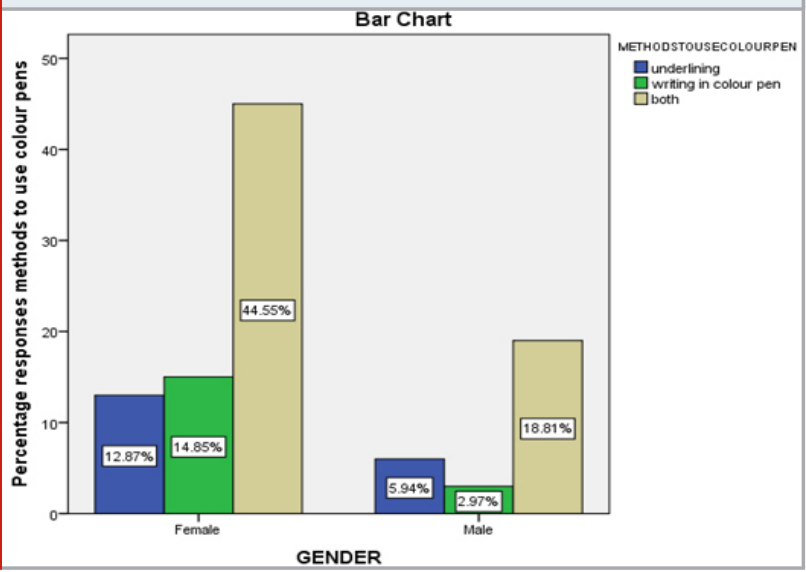

Recently, there is a lack of attention at the high school level in their summative assessments. There are several reasons why an examination of the effect of colour of test in a booklet on exam performance in higher education summative evaluation is important. Colour stimuli may vary on lightness, hue and chromatography(Arthur, 
Cho and Muñoz, 2016). In present study, most of the students i.e.,86\% show increase in grades. For 14\% of them there is no increase in grade. Most of them prefers i.e., 20\% of them prefer pink, green and orange colours. A study has shown that children with autism have some colour coding which makes the children have a motivating learning tool.(Hurley-Hanson, Giannantonio and Griffiths, 2019).

Figure 14: Represents the association between the gender and percentage responses for me on colour pen usage. $\mathrm{X}$ axis represents the gender and $\mathrm{Y}$ axis represents the percentage responses for methods of using colour pens. Majority of females manage the time of examination very well along with the use of colour pens than the males. However the difference is not significant statistically. The $P$ value is $0.506(>0.05)$.

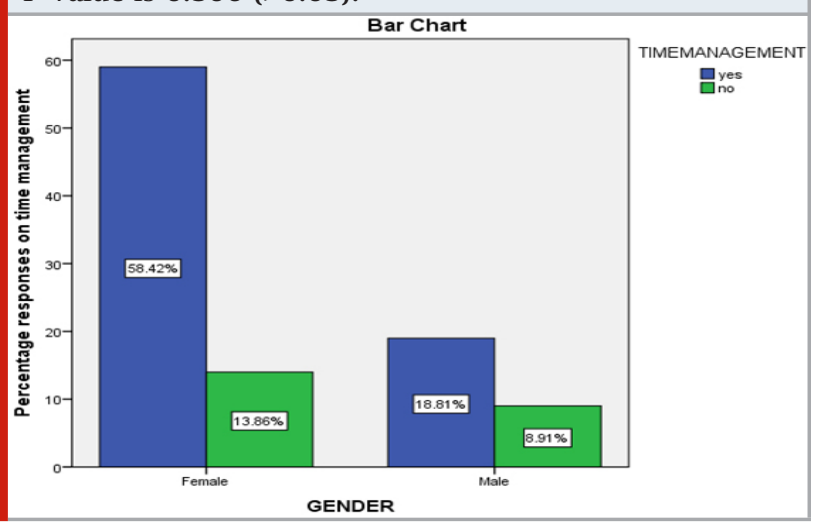

Numerous studies have shown that colours help in learning and remembering the important during examination period. It has also been shown colours also increases the attention towards the studies (Dzulkifli and Mustafar, 2013). Understanding the subject and it concepts based on examination in which the students can write in colour pens during examination with the proper time management will help the students to score excellent marks in forthcoming exams.(Shukla et al., 2014).

\section{CONCLUSION}

From the results of our study, we conclude that the use of colour pens during an exam increases the grade of the student's performance.Eventhough is not statistically significant, in our study we found the females use colour pens in exams more efficiently than males. Also, the study proved that instead the use of colour pens consumed more time than usual, by practice the time can be adjusted sufficiently along with the colour pen use will increase the performance level in their exams.

\section{ACKNOWLEDGEMENTS}

Authors are thankful to the Saveetha Dental College for providing a platform in expressing their knowledge.

Conflicts of Interest: Author declares that there is no conflict of interest.

\section{REFERENCE}

Adams, N. E. (2015) 'bloom's Taxonomy Of Cognitive Learning Objectives', Journal of The Medical Library Association: Jmla. Ncbi.Nlm.Nih.Gov. Available At: Https://Www.Ncbi.Nlm.Nih.Gov/Pmc/Articles/ Pmc4511057/.

Adesoji, F. A. (2018) 'bloom Taxonomy Of Educational Objectives And The Modification Of Cognitive Levels', Advances In Social Sciences Research Journal. Doi: 10.14738/Assrj.55.4233.

Arthur, W., Cho, I. And Muñoz, G. J. (2016) 'red Vs. Green: Does The Exam Booklet Color Matter In Higher Education Summative Evaluations? Not Likely', Psychonomic Bulletin \&t Review, 23(5), Pp. 1596-1601.

Bolloten, B. (2012) 'being Smart - Developing And Writing Equality Objectives', Race Equality Teaching, Pp. 38-41. Doi: 10.18546/Ret.30.2.12.

Chavolla, E. Et Al. (2018) 'color Spaces Advantages And Disadvantages In Image Color Clustering Segmentation', Advances In Soft Computing And Machine Learning In Image Processing, Pp. 3-22. Doi: 10.1007/978-3-31963754-9_1.

Devine, A. (2014) Colour Coding For Learners With Autism: A Resource Book For Creating Meaning Through Colour At Home And School. Jessica Kingsley Publishers.

Dzulkifli, M. A. And Mustafar, M. F. (2013) 'the Influence Of Colour On Memory Performance: A Review', The Malaysian Journal Of Medical Sciences: Mjms, 20(2), Pp. 3-9.

Florea, A. M. And Radu, S. (2007) 'enhancing Penbased Experiences With The Use Of Concept Maps', First International Workshop On Pen-based Learning Technologies (Plt 2007). Doi: 10.1109/Plt.2007.9.

He, W. Et Al. (2016) 'the Effects Of Flipped Instruction On Out-of-class Study Time, Exam Performance, And Student Perceptions', Learning And Instruction, Pp. 61-71. Doi: 10.1016/J.Learninstruc.2016.07.001.

Hurley-hanson, A. E., Giannantonio, C. M. And Griffiths, A. J. (2019) Autism In The Workplace: Creating Positive Employment And Career Outcomes For Generation A. Springer Nature.

Jensen, J. L., Berry, D. A. And Kummer, T. A. (2013) 'investigating The Effects of Exam Length On Performance And Cognitive Fatigue', Plos One. Journals. Plos.Org. Available At: Https://Journals.Plos.Org/ Plosone/Article?Id=10.1371/Journal.Pone.0070270.

Kim, T. H. Et Al. (2011) 'full-colour Quantum Dot Displays Fabricated By Transfer Printing', Nature. Nature.Com. Available At: Https://Www.Nature.Com/ Articles/Nphoton.2011.12/.

Kudliskis, V. And Burden, R. (2009) 'applying "What Works" In Psychology To Enhancing Examination Success In Schools: The Potential Contribution Of Nlp', Thinking Skills And Creativity. Elsevier. Available At: Https://Www.Sciencedirect.Com/Science/Article/Pii/ 
S1871187109000467.

Mascolo, J. T., Alfonso, V. C. And Flanagan, D. P. (2014) Essentials Of Planning, Selecting, And Tailoring Interventions For Unique Learners. John Wiley \& Sons.

Mazzeo, J., Schmitt, A. P. And Bleistein, C. A. (1993) 'sex-related Performance Differences On Constructedresponse And Multiple-choice Sections Of Advanced Placement Examinations', Ets Research Report Series, Pp. I-29. Doi: 10.1002/J.2333-8504.1993.Tb01516.X.

Misra, R. And Castillo, L. G. (2004) 'academic Stress Among College Students: Comparison Of American And International Students', International Journal of Stress Management, Pp. 132-148. Doi: 10.1037/10725245.11.2.132.

Reed, G. Et Al. (2014) 'hyperspectral Imaging Of Gel Pen Inks: An Emerging Tool In Document Analysis',
Science \&t Justice: Journal of The Forensic Science Society. Elsevier, 54(1), Pp. 71-80.

Shukla, S. Et Al. (2014) 'quality Theory Paper Writing For Medical Examinations', Journal Of Clinical And Diagnostic Research: Jcdr, 8(4), Pp. Xc01-xc04.

Umar, A. T. And Majeed, A. (2018) 'the Impact of Assessment For Learning On Students' Achievement In English For Specific Purposes: A Case Study Of Premedical Students At Khartoum University ...', English Language Teaching. Eric. Available At: Https://Eric. Ed.Gov/?Id=Ej1166124.

Wright, C. D., Eddy, S. L. And Wenderoth, M. P. (2016) 'cognitive Difficulty And Format Of Exams Predicts Gender And Socioeconomic Gaps In Exam Performance Of Students In Introductory Biology Courses', Cbe-life Sciences. Am Soc Cell Biol. Available At: Https://Www. Lifescied.Org/Doi/Abs/10.1187/Cbe.15-12-0246. 